\title{
Tratamento osmótico na obtenção de lascas da polpa de pequi (Caryocar brasiliense) desidratadas
}

O pequi é um fruto perecível, com fase de produção de, no máximo, quatro meses ao ano, sendo necessário o desenvolvimento de técnicas que garantam a disponibilidade durante um maior período, mantendo a qualidade e valor nutricional. Diante disso, o presente trabalho propõe um estudo da desidratação osmótica de lascas da polpa do pequi, utilizando cloreto de sódio e sacarose, visando a obtenção de um produto com maior qualidade e propriedades físico-químicas semelhantes ao fruto in natura. Nesse sentido, foi realizando um planejamento experimental fatorial completo $2^{3}$ para determinar as concentrações, proporção fruto: xarope e tempo de imersão, precedido de análises físico-químicas de cinzas; pH; acidez titulável; açucares totais e lipídios. O uso da solução salina não apresenta eficiência, por se tratar de um composto com baixo ponto de saturação, e o fruto só apresenta redução significativa da umidade em soluções osmóticas com concentrações de soluto acima de $50 \%$. Porém, a solução de sacarose foi capaz de reduzir a umidade do fruto de $54,63 \%$ para $31,88 \%$, utilizando a solução de sacarose a 70\%, na proporção 1:2 por 6 horas. A desidratação osmótica também favoreceu o aumento da acidez, cinzas, açucares totais em comparação com o fruto in natura e diminuiu os teores de umidade, pH e lipídios. Dessa forma, o uso do pré-tratamento osmótico pode ser uma alternativa atraente para a conservação do pequi, pois pode ser utilizada uma tecnologia simples e de baixo custo, que permite a obtenção de um produto com características físico-químicas similares ao in natura.

Palavras-chave: Umidade; Cloreto de sódio; Sacarose.

\section{Osmotic treatment in the obtaining of chips of pequi (Caryocar brasiliense) pulp dehydrated}

The pequi is a perishable fruit, with production phase of a maximum of four months to the year, being necessary the development of techniques that guarantee the availability during a greater period, maintaining the quality and nutritional value. Therefore, the present work proposes a study of the osmotic dehydration of pequi pulp flakes, using sodium chloride and sucrose, aiming at obtaining a product with higher quality and physicochemical properties like the fruit in nature. In this sense, a complete 2-factorial experimental design was carried out to determine the concentrations, fruit ratio: syrup and immersion time, preceded by physical-chemical analyzes of ash; $\mathrm{pH}$; titratable acidity; total sugars and lipids. The use of saline solution does not present efficiency, because it is a compound with low saturation point, and the fruit only presents significant reduction of humidity in osmotic solutions with concentrations of solute above $50 \%$. However, the sucrose solution was able to reduce the humidity of the fruit from $54.63 \%$ to $31.88 \%$, using the 70\% sucrose solution in a 1: 2 ratios for 6 hours. Osmotic dehydration also favored the increase of acidity, ashes, total sugars in comparison with the fruit in nature and decreased moisture, $\mathrm{pH}$ and lipid contents. Thus, the use of osmotic pretreatment can be an attractive alternative for the conservation of pequi, since a simple and low-cost technology can be used, which allows obtaining a product with physic-chemical characteristics like in nature.

Keywords: Moisture; Sodium chloride; Sucrose.

Topic: Ciência de Alimentos

Reviewed anonymously in the process of blind peer

Deyse Fernandes da Silva

Universidade do Estado do Mato Grosso, Brasil

http://lattes.cnpq.br/241496764237400

noivosdeyseerafael@hotmail.com

César Vinicius Toniciolli Rigueto iD

Universidade do Estado do Mato Grosso, Brasil

http://lattes.cnpq.br/5053497434546209

http://orcid.org/0000-0003-2778-5170

cesartoniciolli@gmail.com

Raquel Aparecida Loss

Universidade do Estado do Mato Grosso, Brasil

http://lattes.cnpq.br/3925129970802016

raquelloss@unemat.br
Received: 16/07/2017

Approved: 19/10/2017

\author{
Sumaya Ferreira Guedes \\ Universidade do Estado do Mato Grosso, Brasil \\ http://lattes.cnpq.br/87098665855453750 \\ http://orcid.org/0000-0001-7901-1316 \\ su_sumaya@yahoo.com.br \\ José Wilson Pires Carvalho \\ Universidade do Estado do Mato Grosso, Brasil \\ http://lattes.cnpq.br/2176774421270422 \\ jwilsonc@unemat.br
}

\section{Referencing this:}

SILVA, D. F.; RIGUETO, C. V. T.; LOSS, R. A.; GUEDES, S. F.; CARVALHO, J. W. P.. Tratamento osmótico na obtenção de lascas da polpa de pequi (Caryocar brasiliense) desidratadas. Natural Resources, v.7, n.1, p.1-8, 2017. DOI: http://doi.org/10.6008/SPC2237$\underline{9290.2017 .001 .0001}$ 


\section{INTRODUÇÃO}

Dentre as árvores típicas do cerrado, o pequizeiro possui grande incidência e o fruto serve de fonte de renda para vários produtores de pequeno porte (AQUINO et al., 2009). A produção de pequi é considerada uma atividade rentável e sustentável, pois produz lucro sem degradar o meio ambiente, além de ser considerada uma atividade de reflorestamento por se tratar de uma árvore protegida por lei, segundo a Portaria no 54 de 1987 do Instituto Brasileiro de Desenvolvimento Florestal.

O pequi é um fruto sazonal com safra entre os meses de novembro e fevereiro, podendo haver variações dependendo do estado brasileiro. Por ser fonte de renda da população do cerrado, tem sido desenvolvido voltado para o processamento da polpa buscando melhorias na qualidade de seus derivados e diminuição da deterioração do fruto durante a estocagem (FIGUEIRA, 2014).

A desidratação osmótica é indicada como um método alternativo para redução de água presente em alimentos geralmente precedida de secagem ou desidratação. O uso de pré-tratamentos, como a desidratação osmótica, tem sido amplamente estudado para a conservação da qualidade do produto alimentar. Neste procedimento, não existe necessidade de aquecimento da amostra, pois o alimento é imerso em uma solução hipertônica com perda de água e ganho de sólidos (CORREA et al., 2011).

O processo de desidratação faz aumentar a vida útil dos alimentos perecíveis através da diminuição da quantidade de água em seu interior, levando a uma diminuição na degradação enzimática e microbiológica do mesmo. Para que esse processo seja considerado satisfatório, o alimento desidratado deve apresentar os mesmos nutrientes de sua forma in natura ou com perdas pouco significativas, além de manter minimizada a atuação microbiológica que ocasiona a degradação do produto (EMBRAPA, 2010).

O processo de remoção de água dos alimentos mais utilizado nas industrias é a secagem convectiva por ser de fácil implementação. Porém, este processo exige temperaturas elevadas que podem ocasionar degradação dos nutrientes e alterações sensoriais, como cor e textura no alimento (FIGUEIRA, 2014). Tendo em vista que o pequi é um fruto com fase de produção de no máximo de quatro meses é necessário o desenvolvimento de técnicas que garantem a disponibilidade durante um maior período, garantindo a qualidade e valor nutricional (EMATER, 2002).

Diante disso, o presente trabalho propõe um estudo da desidratação osmótica de lascas da polpa do pequi, com dois solutos diferentes, o cloreto de sódio e a sacarose, visando a obtenção de um produto com maior qualidade e propriedades físico-químicas semelhantes ao fruto in natura. Nesse sentido, foi realizando um planejamento experimental fatorial completo $2^{3}$ para determinar as concentrações, proporção fruto: xarope e tempo de imersão, precedido de secagem em estufa de circulação de ar a $60{ }^{\circ} \mathrm{C}$ a fim de comparar o tempo da secagem. 


\section{METODOLOGIA}

\section{Obtenção da matéria prima}

O pequi (Cariocar brasiliense) foi obtido na cidade de Baús-MT, por colheita manual. Para a realização dos estudos foram selecionados os frutos sadios, sem injúrias, sendo transportados até o local de processamento em caixas térmicas, a temperatura ambiente. Todos os frutos, ainda com cascas, foram higienizados com detergente comercial, água corrente e imersos por cinco minutos em solução de hipoclorito de sódio $10 \%(\mathrm{v} / \mathrm{v})$. A despolpa foi realizada manualmente com faca de aço inox previamente esterilizado em álcool 70\% (v/v). Foram cortadas lascas com tamanho variando de 4 a $6 \mathrm{~cm}$ de comprimento, acondicionadas em embalagem de polietileno e congeladas a $-18^{\circ} \mathrm{C}$ até a realização do tratamento osmótico, secagem convectiva e análises físico-químicas.

\section{Tratamento osmótico}

As soluções para o pré-tratamento osmótico foram elaboradas com dois compostos: cloreto de sódio $(\mathrm{NaCl})$ e sacarose $\left(\mathrm{C}_{12} \mathrm{H}_{22} \mathrm{O}_{11}\right)$ em diferentes concentrações, conforme delineamentos experimentais empregados nos ensaios. As lascas da polpa de pequi foram descongeladas a temperatura ambiente e imersas nas soluções de cloreto de sódio ou sacarose para desidratação osmótica. Após a desidratação osmótica, as lascas de pequi foram secas submetidas à etapa de secagem em estufa a 105 ㄷ $\mathrm{C}$ a fim de acompanhar a perda de água no tratamento osmótico.

Tabela 1: Variáveis e níveis estudados no planejamento fatorial completo $2^{3}$ no tratamento osmótico de lascas de polpa de pequi.

\begin{tabular}{|c|c|c|c|}
\hline \multicolumn{4}{|c|}{ Solução salina de cloreto de sódio } \\
\hline Variáveis/Níveis & Solução osmótica (\%) ${ }^{*}$ & Fruto:xarope $(\mathrm{g} / \mathrm{mL})$ & Tempo (h) \\
\hline-1 & 5 & $1: 2$ & 2 \\
\hline 0 & 15 & $1: 4$ & 4 \\
\hline 1 & 25 & 1:6 & 6 \\
\hline \multicolumn{4}{|c|}{ Solução de sacarose } \\
\hline Variáveis/Níveis & Solução osmótica (\%)* & Fruto:xarope (g/mL) & Tempo (h) \\
\hline-1 & 50 & $1: 2$ & 6 \\
\hline 0 & 60 & $1: 4$ & 10 \\
\hline 1 & 70 & 1:6 & 14 \\
\hline
\end{tabular}

${ }^{*}$ Cloreto de sódio ou sacarose

Para avaliar as variáveis que interferem na desidratação osmótica da polpa de pequi, realizou-se o planejamento fatorial completo $2^{3}$ com três pontos centrais, onde as variáveis de estudo foram a concentração do soluto da solução de desidratação osmótica, proporção fruto: xarope e tempo de imersão. Para ambas as soluções salinas foram empregadas o mesmo tipo de delineamento experimental, porém com valores diferentes nos níveis estudados, como mostra a tabela 1. O ponto central utilizado para a solução de sacarose foi determinado segundo os resultados obtidos em planejamento fatoriais anteriormente executados.

Os resultados obtidos nos planejamentos com as diferentes soluções osmóticas foram avaliados em termos do teor de umidade (\%) e submetidos à análise estatística usando o software Statistica 7,0. 0 ensaio 
que apresentou o menor teor de umidade foi realizado novamente em triplicata para realização das análises físico-químicas.

\section{Análises físico-químicas}

As análises físico-químicas de $\mathrm{pH}$, acidez, lipídios, umidade e cinzas foram realizadas conforme a metodologia descrita pelo Instituto Adolfo Lutz (2008) e os açúcares totais foram quantificados pelo método DNS reportado por Maldonade et al. (2013), todas em triplicatas. Para realização das análises físico-químicas foi usado potenciômetro de bancada MARCONI (PA200, Brasil), mufla QUIMIS (Q318M21) e espectrofotômetro AMALYSER (800N).

\section{RESULTADOS}

\section{Desidratação osmótica com solução salina de cloreto de sódio}

A eficiência da desidratação utilizando a solução de cloreto de sódio $(\mathrm{NaCl})$ foi realizada a partir da análise do teor de umidade obtida no experimento fatorial completo $2^{3}$, onde é possível observar que após o tratamento osmótico, a umidade aumentou para todos os ensaios, indicando reidratação, conforme apresentado na tabela 2.

Tabela 2: Matriz do planejamento fatorial completo $2^{3} \mathrm{com}$ as variáveis e reais e codificadas, com as respostas expressas em termos de umidades, no tratamento osmótico das lascas de polpa de pequi.

\begin{tabular}{|c|c|c|c|c|}
\hline Experimento & Solução $\mathrm{NaCl}(\%)$ & Fruta:Xarope (g:mL) & Tempo (h) & Umidade (\%) \\
\hline Fruto in natura & - & - & - & 54,63 \\
\hline 1 & $-1(5)$ & $-1(1: 2)$ & $-1(2)$ & 66,50 \\
\hline 2 & $1(25)$ & $-1(1: 2)$ & $-1(2)$ & 63,61 \\
\hline 3 & $-1(5)$ & $1(1: 6)$ & $-1(2)$ & 68,12 \\
\hline 4 & $1(25)$ & $1(1: 6)$ & $-1(2)$ & 58,31 \\
\hline 5 & $-1(5)$ & $-1(1: 2)$ & $1(6)$ & 66,19 \\
\hline 6 & $1(25)$ & $-1(1: 2)$ & $1(6)$ & 54,77 \\
\hline 7 & $-1(5)$ & $1(1: 6)$ & $1(6)$ & 63,68 \\
\hline 8 & $1(25)$ & $1(1: 6)$ & $1(6)$ & 55,91 \\
\hline 9 & $0(15)$ & $0(1: 4)$ & $0(4)$ & 59,79 \\
\hline 10 & $0(15)$ & $0(1: 4)$ & $0(4)$ & 58,57 \\
\hline 11 & $0(15)$ & $0(1: 4)$ & $0(4)$ & 58,39 \\
\hline
\end{tabular}

Os resultados obtidos foram submetidos à análise estatística para avaliar a influência dos parâmetros utilizados em relação à perda de umidade do fruto, conforme apresentado na Figura 1. Utilizou-se um Diagrama de Pareto, para que fossem observados os efeitos das variáveis em relação à desidratação osmótica do pequi com solução salina $(\mathrm{NaCl})$.

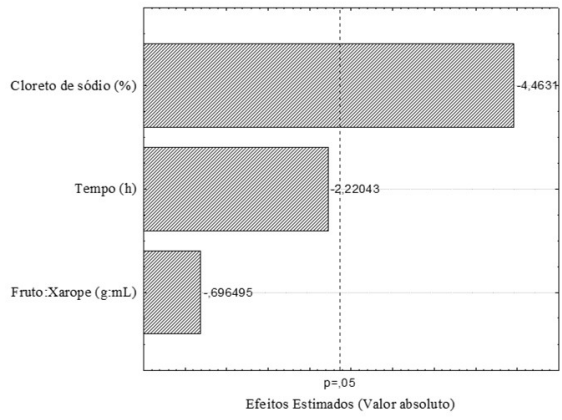

Figura 1: Diagrama de Pareto dos efeitos das variáveis em relação à desidratação osmótica do pequi com solução salina $(\mathrm{NaCl})$. 


\section{Desidratação osmótica com solução de sacarose}

A Tabela 3 apresenta a umidade final das lascas de polpas de pequi submetidas ao tratamento osmótico com solução de sacarose, nas condições determinadas pelo planejamento fatorial completo $2^{3}$, bem como a umidade do fruto in natura.

Tabela 3: Matriz do planejamento fatorial completo $2^{3}$ com as variáveis e reais e codificadas, com as respostas expressas em termos de umidades, no tratamento osmótico das lascas de polpa de pequi.

\begin{tabular}{|c|c|c|c|c|}
\hline Experimento & Solução sacarose (\%) & Fruta: Xarope (g:mL) & Tempo (h) & Umidade (\%) \\
\hline Fruto in natura & - & - & - & 54,63 \\
\hline 1 & $-1(50)$ & $-1(1: 2)$ & $-1(6)$ & 43,15 \\
\hline 2 & $1(70)$ & $-1(1: 2)$ & $1(6)$ & 31,88 \\
\hline 3 & $-1(50)$ & $1(1: 6)$ & $-1(6)$ & 40,60 \\
\hline 4 & $1(70)$ & $1(1: 6)$ & $-1(6)$ & 35,0 \\
\hline 5 & $-1(50)$ & $-1(1: 2)$ & $1(14)$ & 37,71 \\
\hline 6 & $1(70)$ & $-1(1: 2)$ & $1(14)$ & 34,80 \\
\hline 7 & $-1(50)$ & $1(1: 6)$ & $1(14)$ & 31,29 \\
\hline 8 & $1(70)$ & $1(1: 6)$ & $1(14)$ & 34,29 \\
\hline 9 & $0(60)$ & $0(1: 4)$ & $0(10)$ & 38,22 \\
\hline 10 & $0(60)$ & $0(1: 4)$ & $0(10)$ & 40,58 \\
\hline 11 & $0(60)$ & $0(1: 4)$ & $0(10)$ & 38,23 \\
\hline
\end{tabular}

Consoante à proposição realizada na tabela 3 , e semelhante ao que fora idealizado na figura 1 , os resultados obtidos para desidratação osmótica com solução de sacarose foram submetidos à análise estatística para avaliação dos parâmetros utilizados, de acordo com a Figura 2, na qual se utilizou um Diagrama de Pareto dos efeitos das variáveis em relação à desidratação osmótica do pequi com solução de sacarose $\left(\mathrm{C}_{12} \mathrm{H}_{22} \mathrm{O}_{11}\right)$.

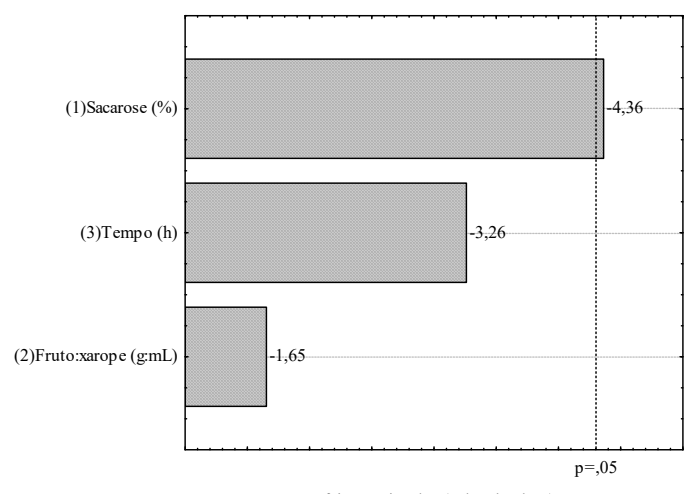

Figura 2: Diagrama de Pareto dos efeitos das variáveis em relação à desidratação osmótica do pequi com solução de sacarose $\left(\mathrm{C}_{12} \mathrm{H}_{22} \mathrm{O}_{11}\right)$.

Realizou-se uma caracterização físico-química do pequi (Caryocar brasiliense) in natura e após o prétratamento osmótico. Conforme se pode verificar na Tabela 4, é possível observar os resultados das análises físico-químicas da polpa de pequi in natura, e após o tratamento osmótico, que favoreceu o menor teor de umidade do fruto.

Tabela 4: Parâmetros físico-químicos da polpa de pequi in natura e após tratamento osmótico.

\begin{tabular}{|c|c|c|}
\hline Parâmetro avaliado & Fruto in natura & Melhor condição* \\
\hline Umidade (\%) & $54,63 \pm 0,18$ & $31,88 \pm 0,10$ \\
\hline Resíduo mineral fixo (\%) & $0,38 \pm 0,02$ & $0,69 \pm 0,08$ \\
\hline Acidez titulável & $0,70 \pm 0,05$ & $1,2 \pm 0,075$ \\
\hline $\mathrm{pH}$ & $6,78 \pm 0,18$ & $5,92 \pm 0,02$ \\
\hline Açúcar total (\%) & $2,77 \pm 0,09$ & $4,31 \pm 0,15$ \\
\hline Lipídios (\%) & 31 & 23,08 \\
\hline
\end{tabular}

${ }^{*}$ Imersão dos frutos em solução de sacarose a 70\% por 6 horas na proporção fruto xarope 1:2. 


\section{DISCUSSÃO}

\section{Desidratação osmótica com solução salina de cloreto de sódio}

Analisando a tabela 2 , verifica-se que houve uma reidratação do fruto, que pode ser justificada pelo baixo teor de umidade do próprio fruto, exigindo condições extremas para que ocorra a desidratação, uma vez que o teor máximo de concentração da solução osmótica foi de $25 \% \mathrm{de} \mathrm{NaCl}(\mathrm{m} / \mathrm{v})$, valor inferior ao teor de sólidos presentes no próprio fruto (54\%).

O diagrama de Pareto proposto na Figura 1 indica estatisticamente que, quanto maior a concentração do sal, menor o teor de umidade do fruto, sugerindo que a concentração salina da solução fosse aumentada. Diante disso, foi realizado um teste preliminar para verificar qual o ponto máximo de saturação para a solução de cloreto de sódio, utilizando as concentrações de $20 \%, 30 \%, 40 \%$, e 60\% (m/v). Entretanto, devido ao Kps da solução de cloreto de sódio, a solução salina tornou-se supersaturada em concentrações superiores a $30 \%$, impossibilitando o aumento da concentração osmótica.

\section{Desidratação osmótica com solução de sacarose}

O uso da sacarose para o tratamento osmótico tem como apelo a aceitabilidade, palatabilidade, alta disponibilidade, baixo custo de produção, alta pressão osmótica da solução aquosa e alta solubilidade em água, fatores que favorecem a sua utilização neste tipo de tratamento (MARTIM, 2006). De acordo com os resultados obtidos no tratamento osmótico com solução de sacarose, verificável na tabela 3, é possível observar uma redução da umidade de 54,63\% do fruto in natura para 31,88 e 31,29\% no tratamento 2 e 7, respectivamente. Observa-se que altas concentrações de sacarose ( $70 \%$ - ensaio 2$)$ e elevado tempo de imersão do fruto na solução osmótica (14 horas - ensaio 7) favoreceram os menores teores de umidade. Este dado é confirmado no diagrama de Pareto mostrado na Figura 2, onde verifica-se que maiores concentrações de sacarose e maior tempo favorecem a redução da umidade.

Segundo Santos (2013), a qualidade da desidratação osmótica depende de fatores como a concentração, o tipo de agente osmótico, a pressão de trabalho, o tempo de imersão, a natureza do produto e a área de superfície exposta à troca osmótica. Como pode ser observado, mesmo que não seja considerada significativa estatisticamente, maiores concentrações na solução osmótica favorecem a desidratação dos produtos, incluindo de frutos que apresentam baixos teores de umidade como o pequi.

Assim, com o aumento da concentração de solutos da solução, há um aumento na pressão osmótica sobre a polpa da fruta, resultando em uma maior difusão de água do alimento para a solução e consequentemente inserção do soluto para o fruto. Em um estudo realizado por Martim (2006), o autor observou um decréscimo de $73,44 \%$ na umidade da manga (Mangifera indica I.) para 31,45\% após desidratação osmótica com sacarose, mostrando um efeito significativo na redução da atividade de água presente este alimento.

Dessa forma, a escolha da melhor condição do tratamento osmótico foi realizada a partir do menor teor de umidade $(31,88 \%)$, considerando o menor tempo de imersão (6 horas) e a maior concentração de 
sacarose (70 \%). A condição selecionada foi realizada novamente em triplicata, e os parâmetros físicoquímicos avaliados para comparação com o fruto in natura.

\section{Caracterização físico-química do pequi (Caryocar brasiliense) in natura e após o pré-tratamento osmótico}

Os dados apresentados na tabela 4 mostram que o processo de desidratação osmótica pode influenciar no teor de resíduo mineral fixo (cinzas) do produto, sendo que o conteúdo de cinzas da amostra in natura é inferior ao teor para a polpa desidratada. Isso pode ser justificado, pelo aumento da concentração dos minerais no fruto depois do processo de desidratação (LIMA et al., 2007).

Após a realização do tratamento osmótico, nota-se um aumento da acidez da polpa de pequi, proposto na tabela 4. A acidez contribui para o sabor e aroma, e o seu valor indica a quantidade de ácidos orgânicos presentes. Os ácidos orgânicos são produtos intermediários do metabolismo respiratório dos frutos e como decorrer do tempo de armazenamento pode acarretar no aumento da acidez do fruto (CORREIA et al., 2011).

Como consequência do aumento da acidez, é possível observar que o tratamento osmótico fez diminuir o valor do $\mathrm{pH}$ da polpa do fruto. $\mathrm{O}$ valor obtido do fruto in natura foi de $6,78 \pm 0,18$ semelhante ao encontrado nos estudos realizados por Oliveira et al. (2010) e Vera et al. (2007) de 6,9 e 6,58, respectivamente. Após o tratamento osmótico o valor do pH decresceu para 5,92 $\pm 0,02$.

$\mathrm{O}$ tratamento osmótico também promoveu um aumento dos açúcares totais (Tabela 4) associado à incorporação de sólidos pela polpa durante a imersão na solução de sacarose. Segundo Paglarini et al. (2013), durante o processo de desidratação osmótica as paredes celulares atuam como membranas semipermeáveis, deixando assim que ocorra a liberação da água e incorporando os sólidos da solução.

Quanto ao teor de lipídios, a fruta in natura apresentou 31\% e após o tratamento houve uma redução para 23,08\% (Tabela 4). Isso se deve ao fato que a interação dos componentes do fruto com a solução osmótica acarreta a eliminação para a fase aquosa de substâncias da polpa de grande valor nutritivo e sensorial, como vitaminas, lipídios, minerais, e compostos aromáticos (GONÇALVES et al., 2008).

\section{CONCLUSÕES}

O uso da solução salina no processo osmótico do fruto de pequi não apresenta eficiência, por se tratar de um composto com baixo ponto de saturação e o fruto só apresenta redução significativa da umidade em soluções osmóticas com concentrações de soluto acima de $50 \%$. Entretanto, a solução de sacarose apresentou uma eficiência significativa no processo de desidratação osmótica, incluindo na intensificação na cor dor fruto que se torna desejável.

A imersão das lascas de pequi na solução de sacarose a 70\%, na proporção fruto: xarope 1:2 por 6 horas reduziu a umidade de 54,63 \% para 31,88 \%. A desidratação osmótica também favoreceu o aumento da acidez, cinzas, açucares totais em comparação com o fruto in natura e diminuiu os teores de umidade, $\mathrm{pH}$ e lipídios. Dessa forma, o uso do pré-tratamento osmótico pode ser uma alternativa atraente para a 
conservação do pequi, uma vez que pode ser utilizada uma tecnologia simples e de baixo custo, que permite a obtenção de um produto com características físico-químicas similares ao in natura.

\section{REFERÊNCIAS}

AQUINO, L. P.; FERRUA, F. Q.; BORGES, S. V.; ANTONIASSI, R.; CORRÊA, J. L. G.; CIRILLO, M. A.. Influência da secagem do pequi (Caryocar brasiliense Camb.) na qualidade do óleo extraído. Revista Ciência e Tecnologia de Alimentos, v.29, n.2, 2009.

CORRÊA, J. L. G.; RASIA, M. C.; GARCIA-PEREZ, J. V.; MULET, A.; CARCEL, J. A.. Drying of pineapple by microwave-vacuun with osmotic pretreatment. Drying technology, London, v.29, n.13, 2011.

EMATER. Empresa de Assistência Técnica e Extensão Rural do Estado de Minas Gerais. Fruticultura: A cultura do Pequi (Cayocar Brasiliense). Belo Horizonte: 2002.

EMBRAPA. Empresa Brasileira de Pesquisa Agropecuária. Princípios de secagem de alimentos. Planaltina: 2010.

FIGUEIRA, F. V.. Secagem de Pequi (Caryocar Brasiliensis Camb.) Precedida de Desidratação Osmótica. Dissertação (Mestrado) - Universidade Federal de Lavras, Lavras, 2014.

GONÇALVES, A. A.; BLUME, A. R.. Efeito da desidratação osmótica como tratamento preliminar na secagem do abacaxi. Estudos Tecnológicos, v.4, 2008.

INSTITUTO ADOLFO LUTZ. Métodos físico-químicos para análise de alimentos. São Paulo: Instituto Adolfo Lutz, 2008.

LIMA, A.; SILVA, A. M. O.; TRINDADE, R. A.; TORRES, R. P.; MANCINI-FILHO, J.. Composição química e compostos bioativos presentes na polpa e na amêndoa do pequi (Caryocar brasiliense Camb.). Revista Brasileira de Fruticultura, Jaboticabal, v.29, n.3, 2007.
MALDONADE, I. R.; CARVALHO, P. G. B.; FERREIRA N. A.. Protocolo para determinação de açúcares totais em hortaliças pelo método de DNS. Embrapa Hortaliças, Brasília, 2013.

MARTIM, N. S. P. P.. Estudo das características de processamento da manga (Mangífera indica L.) variedade Tommy Atkins desidratada. Dissertação (Mestrado) - Universidade Federal do Paraná, Curitiba, 2006.

OLIVEIRA, W. L.. Boas práticas de manejo para o extrativismo sustentável do pequi. Brasília: Embrapa Recursos Genéticos e Biotecnologia, 2010.

PAGLARINI, C. S.; SILVA, F. S.; PORTO, A. G.; PIASSON, D.; SANTOS, P.. Histerese das isotermas de sorção da polpa de manga (Mangifera indica L.) variedade manteiga. Revista Brasileira de Engenharia Agrícola e Ambiental, Campina Grande, v.17, n.3, 2013.

SANTOS, D. C.; QUEIROZ, A. J. M.; FIGUEIRÊDO, R. M. F.; OLIVEIRA, E. N. A.. Cinética de secagem de farinha de grãos residuais de urucum. Revista Brasileira de Engenharia Agrícola e Ambiental, Campina Grande, v.17, n.2, 2013.

VERA, R.; SOUZA, E. R. B.; FERNANDES, E. P.; NAVES, R. V.; SOARES JÚNIOR, M. S.; CALIARI, M.; XIMENES, P. A.. Caracterização física e química de frutos do pequizeiro (Caryocar brasiliense Camb.) oriundos de duas regiões no estado de Goiás, Brasil. Revista Pesquisa Agropecuária Tropical, Campina Grande, v.37, n.2, p.93- 99, 2007. 